\title{
Classroom Lessons From Geoscience Undergraduate Research and Presentations
}

WAYNE HAMILTON AND JOE YELDERMAN JR,

BAYLOR UNIVERSITY

MONDAY 10-23-17

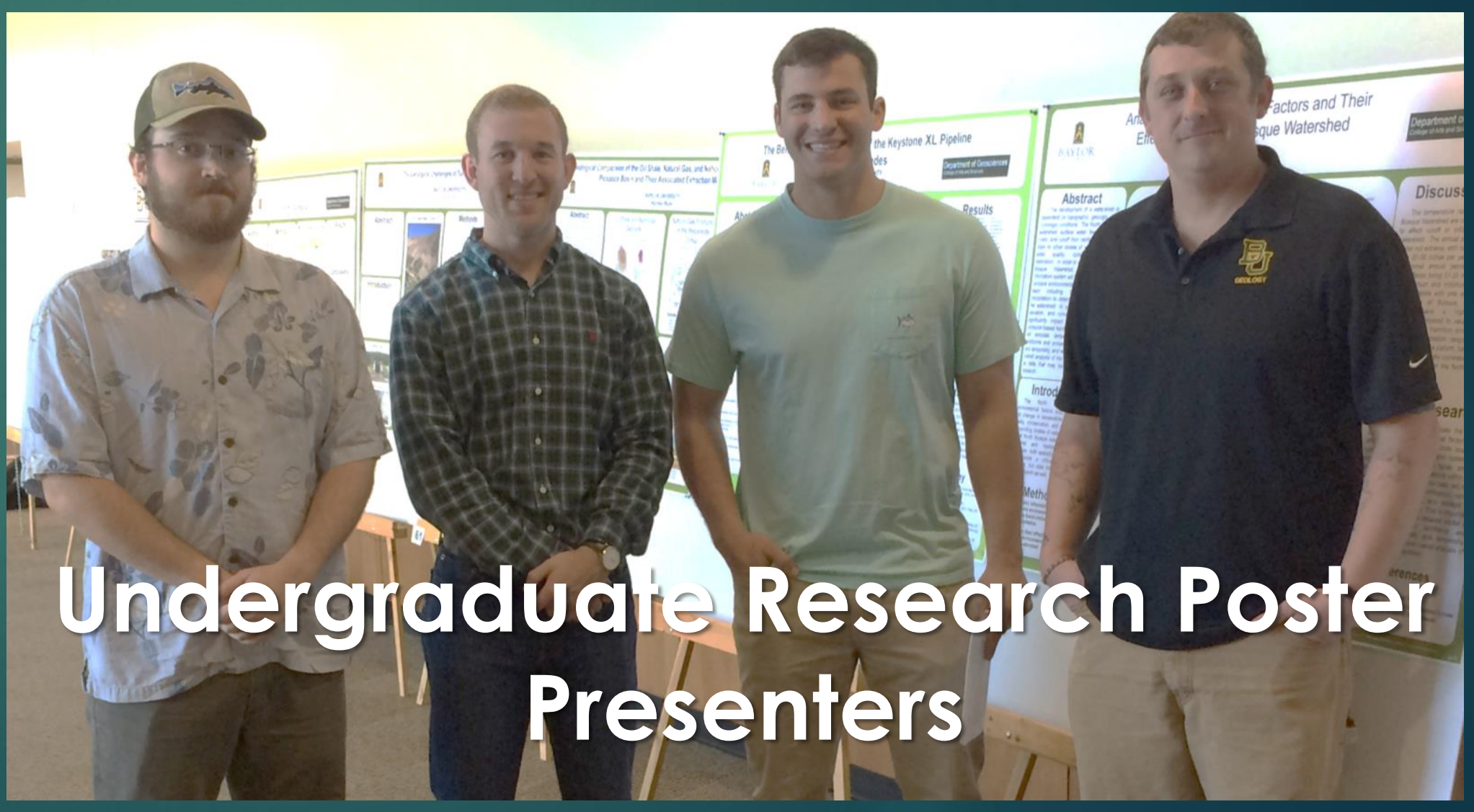




\section{Presentation Overview}

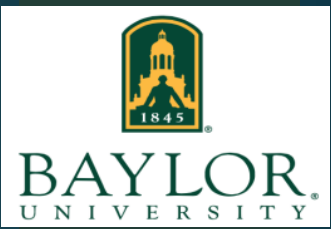

Department of Geosciences College of Arts and Sciences

- Geosciences Research Lessons Learned

> What Worked: Eight Learning Areas

$\checkmark$ Improvements: Four Key Thoughts

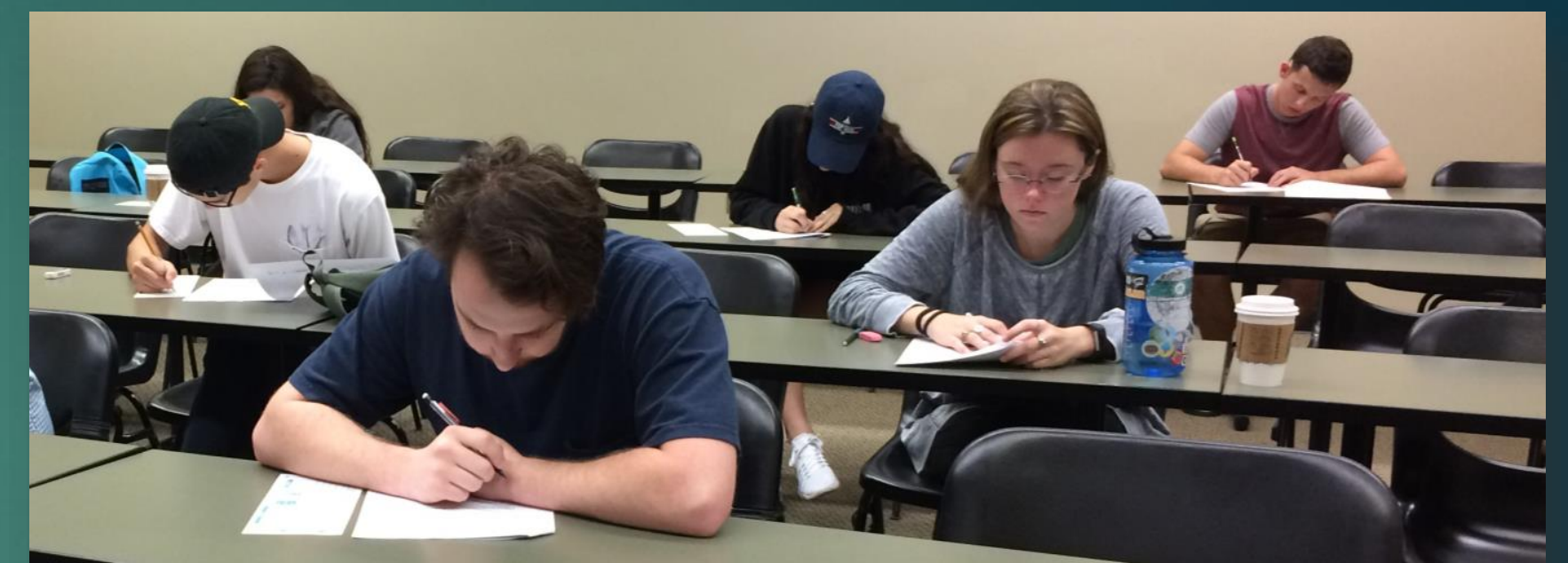

$\checkmark$ Baylor wide undergraduate research

Conclusions

- Key Learnings and Next Steps

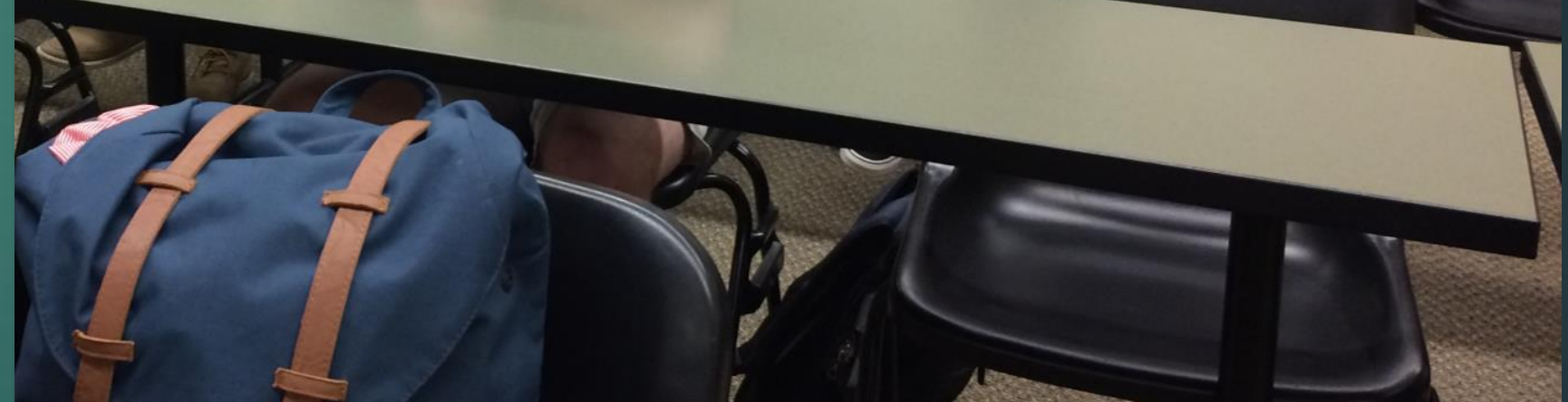

- Undergraduate Environmental Geolo y Class 


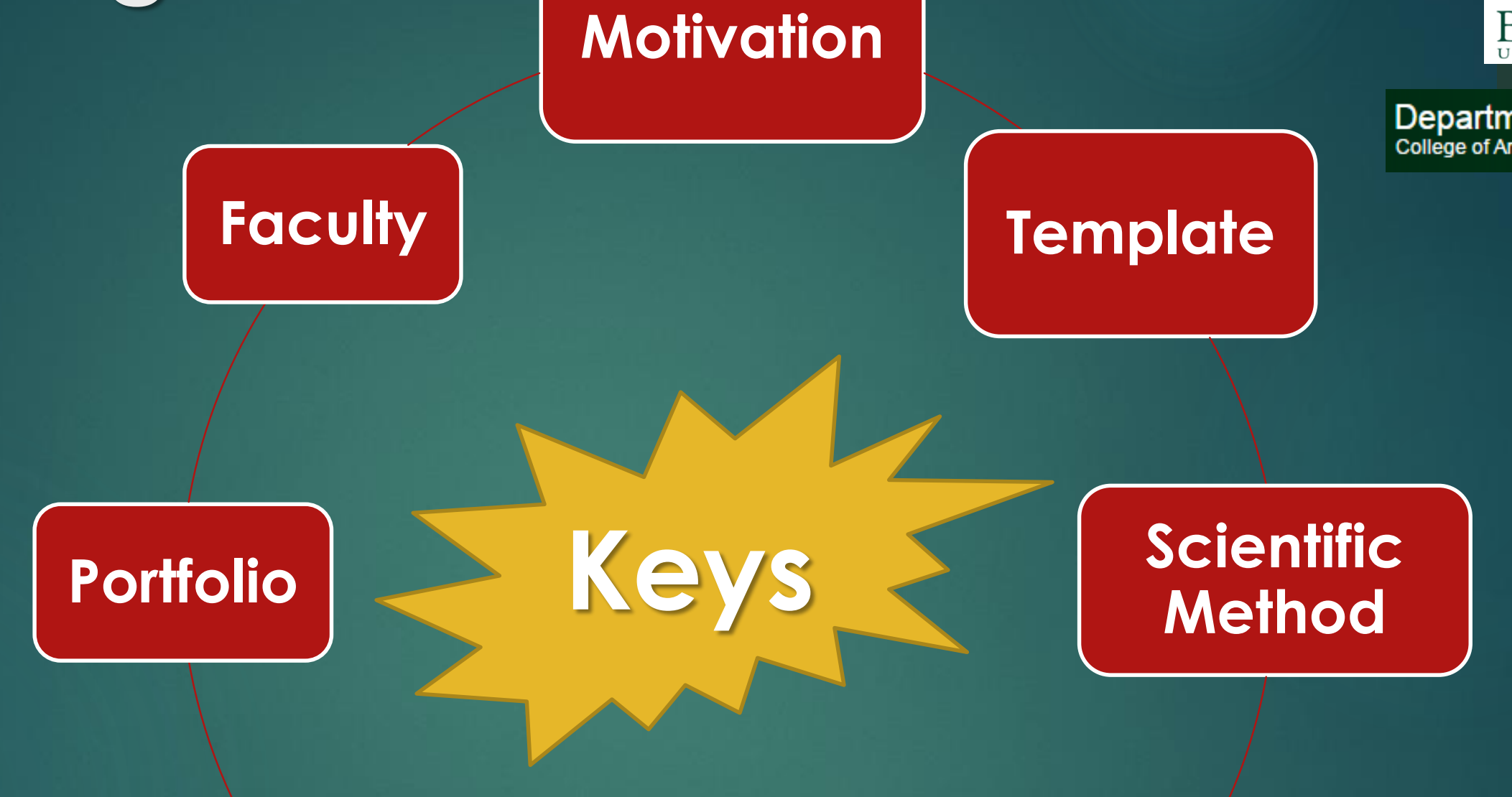

Diversity Deadlines 


\section{Motivation}

> Student's Topic

$\checkmark$ Discussed teacher

$\checkmark$ Weekly Updated

$>$ Displayed

$\checkmark$ Evaluated

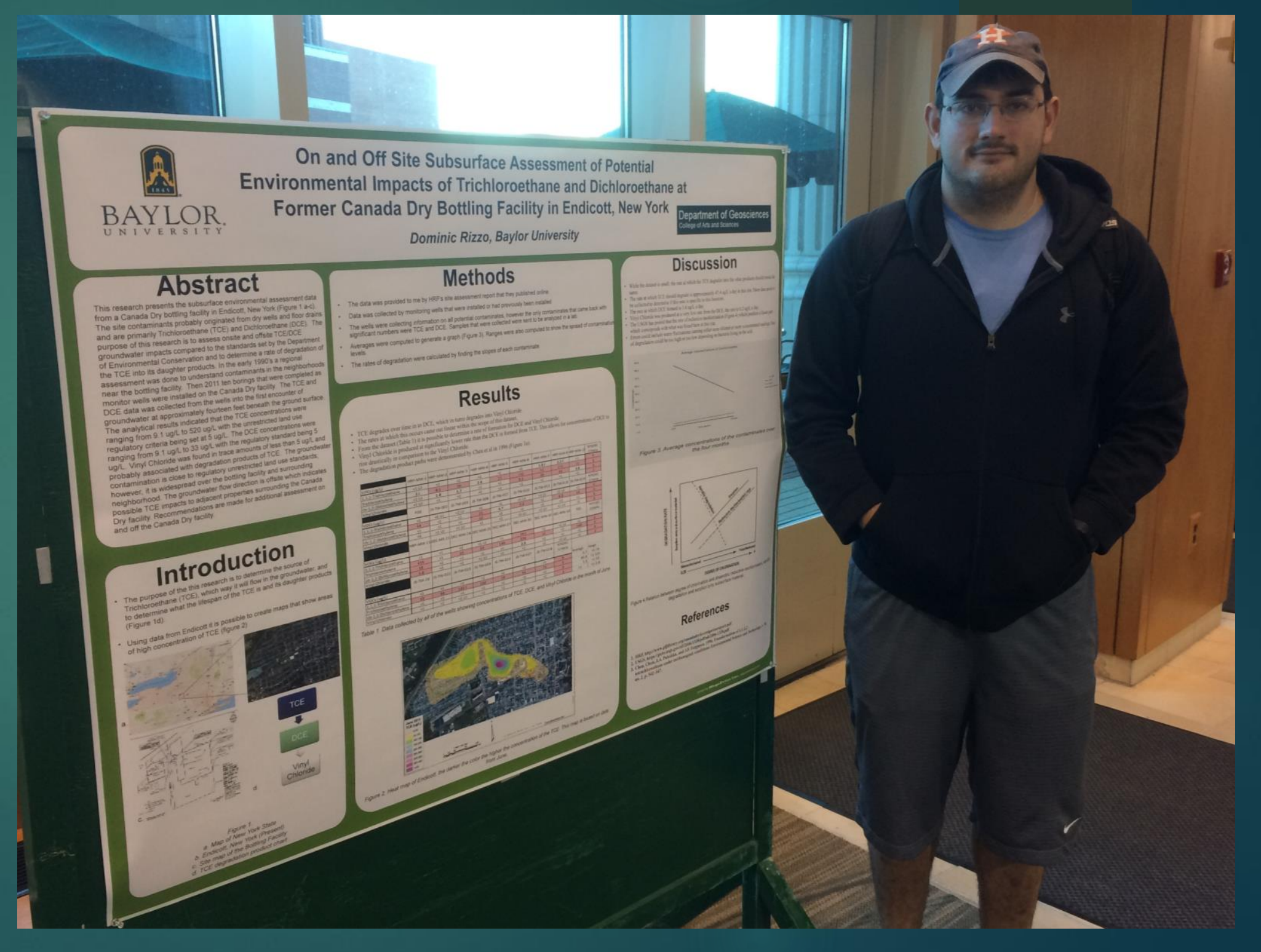




\section{Baylor's Undergraduate Research}

Other Undergradualie Disciplines

1. Economics

2. Engineering

3. Communicolijons

4. Religjion

5. Fannily and Consumer Sciences

6. Modern Foreign Lønguoges

7. Stajistics

8. Fominily and Consumer Sciences

\%. Heolfin, hunnan Perfornance ond Recreglion

10. Physics

1]. psychology

12. Chemistisy

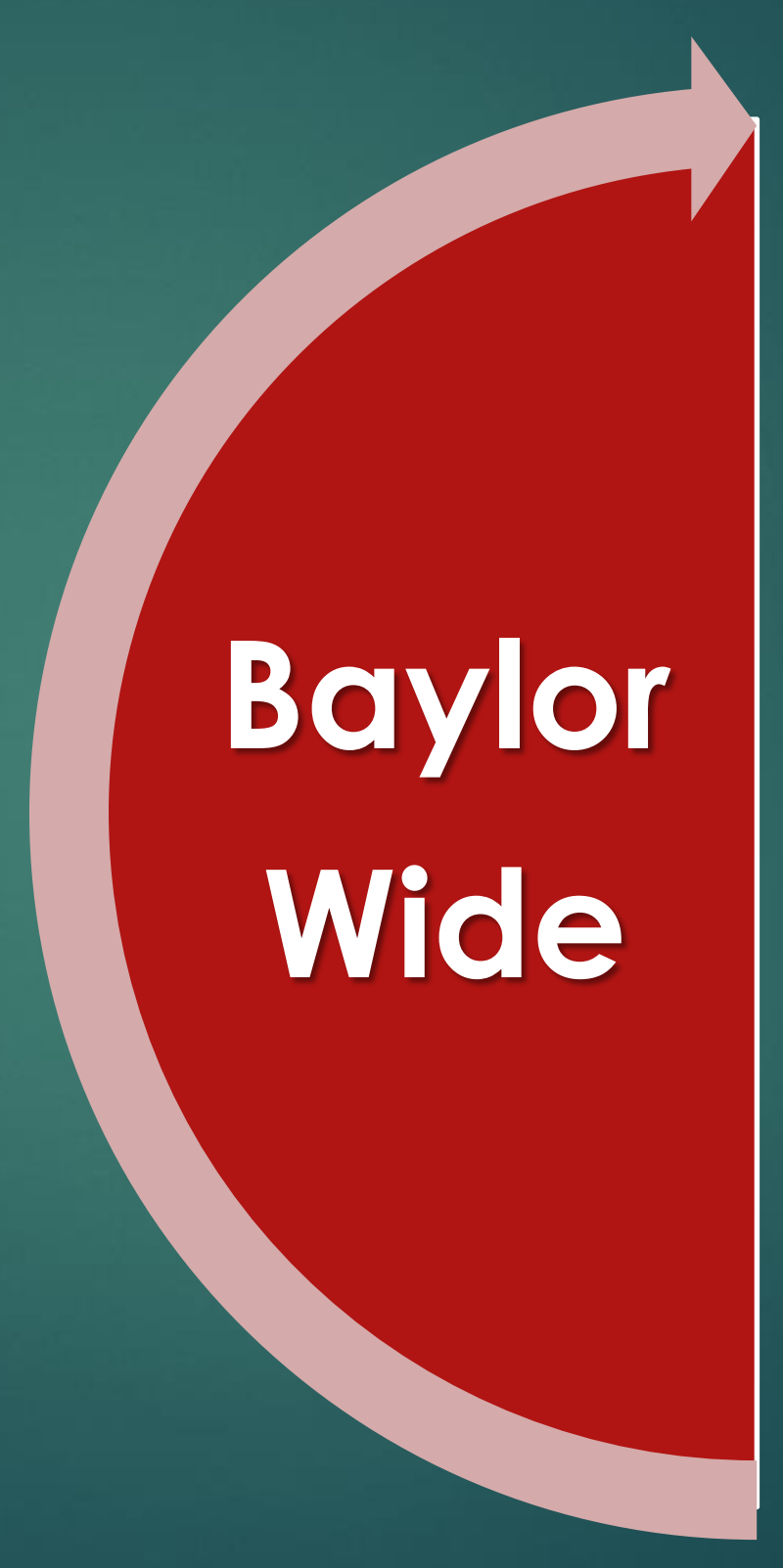

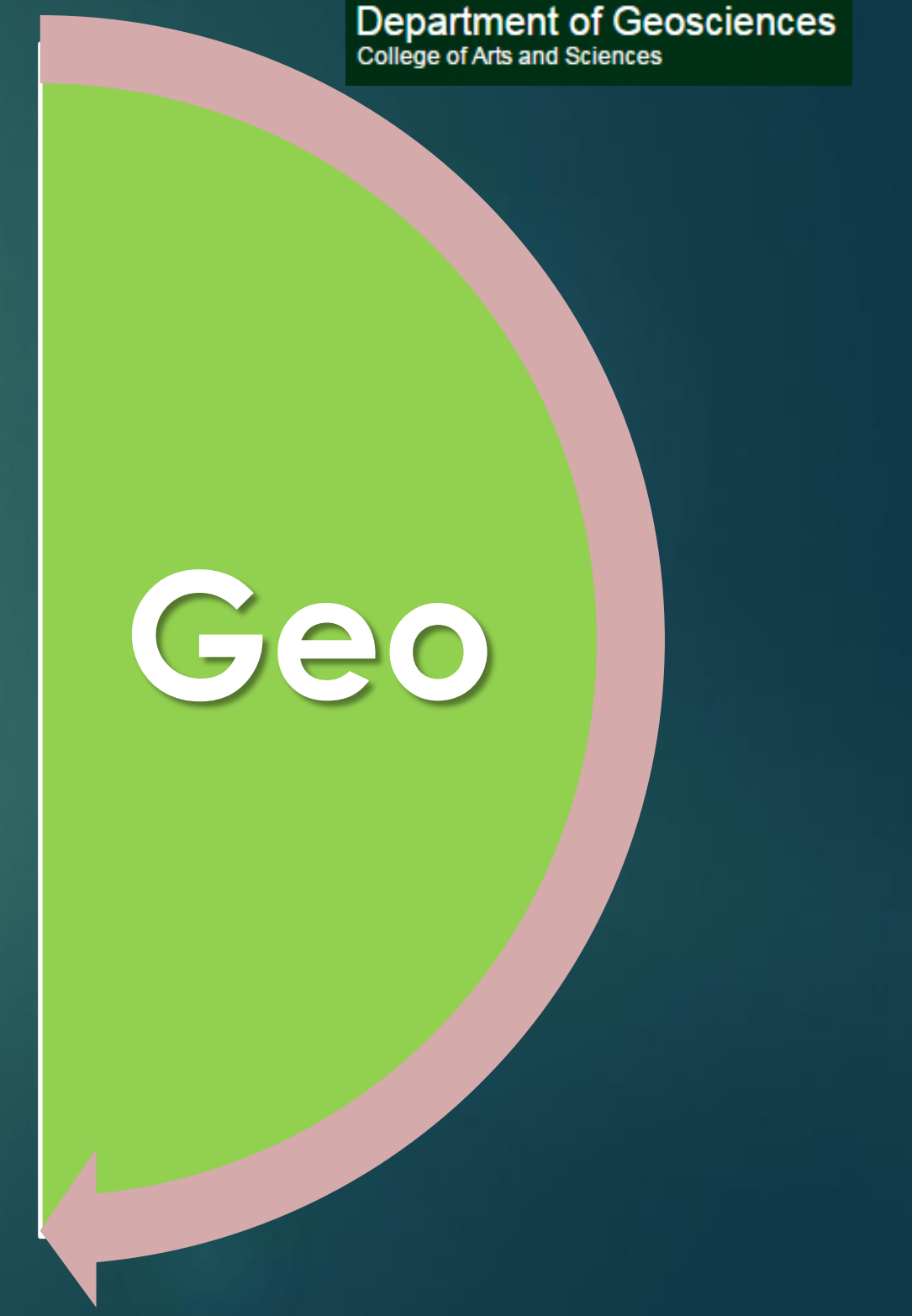




\section{Template}

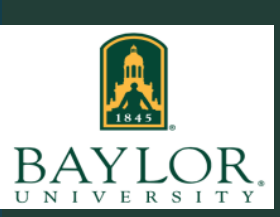

- Starting Point

- Key Areas

$>$ Just Start

- Works for Most Projects

- Compare and Contrast

$\checkmark$ Format Challenges

$\checkmark$ Best Practices

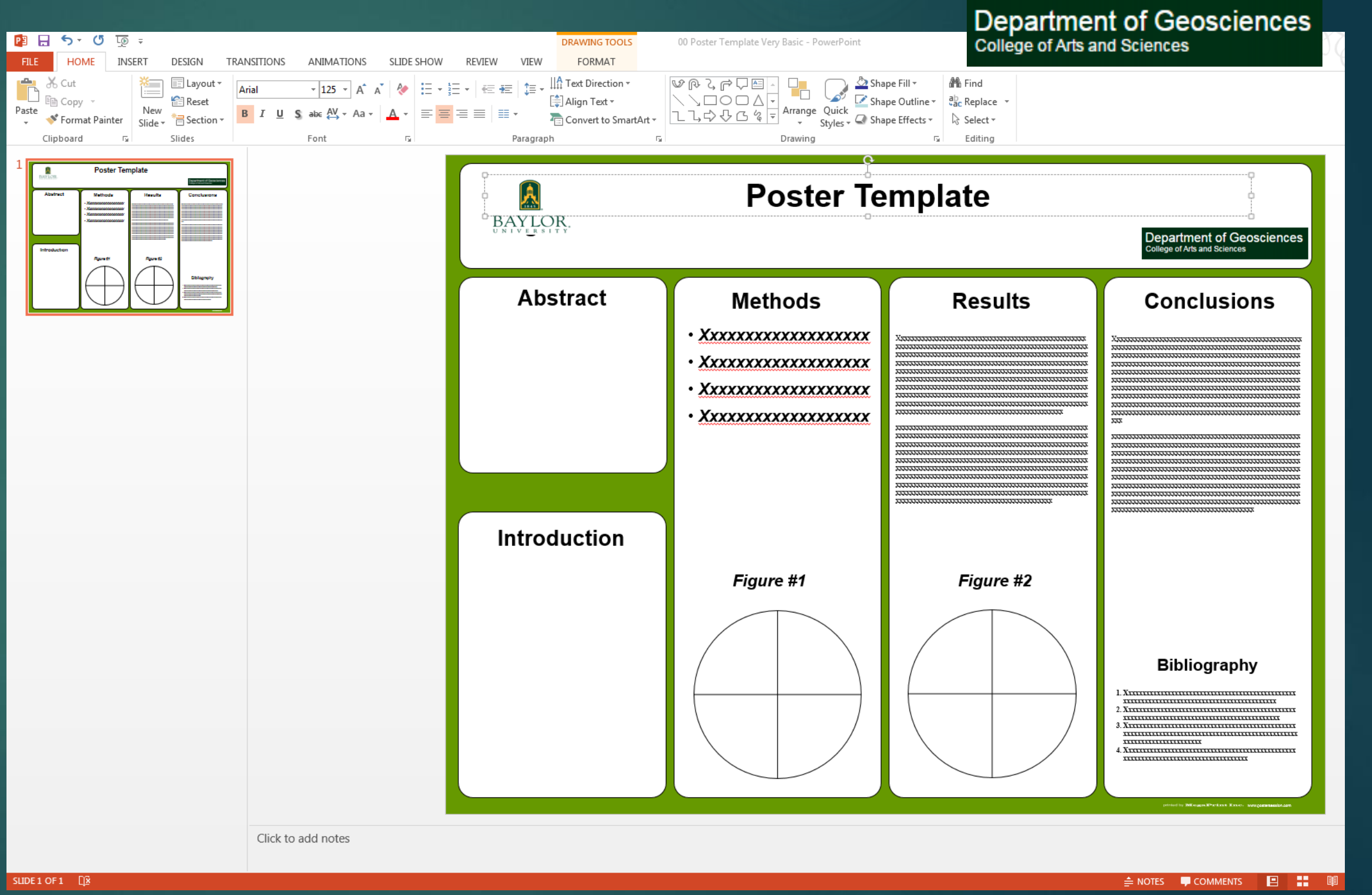




\section{Template}

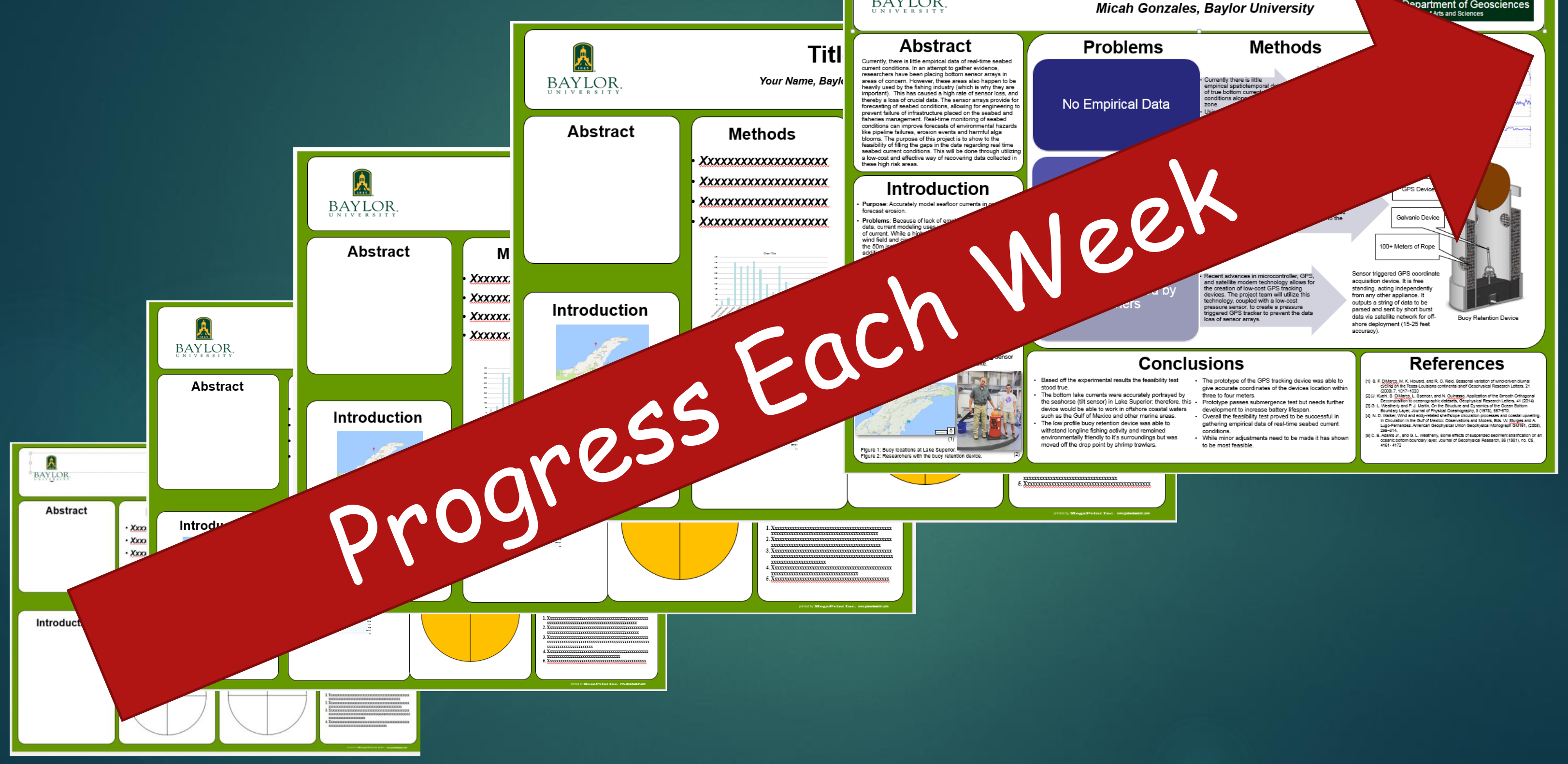




\section{Scientific Method}

Each Week We'll Focus on each part of your poster

You'll present class to keep current

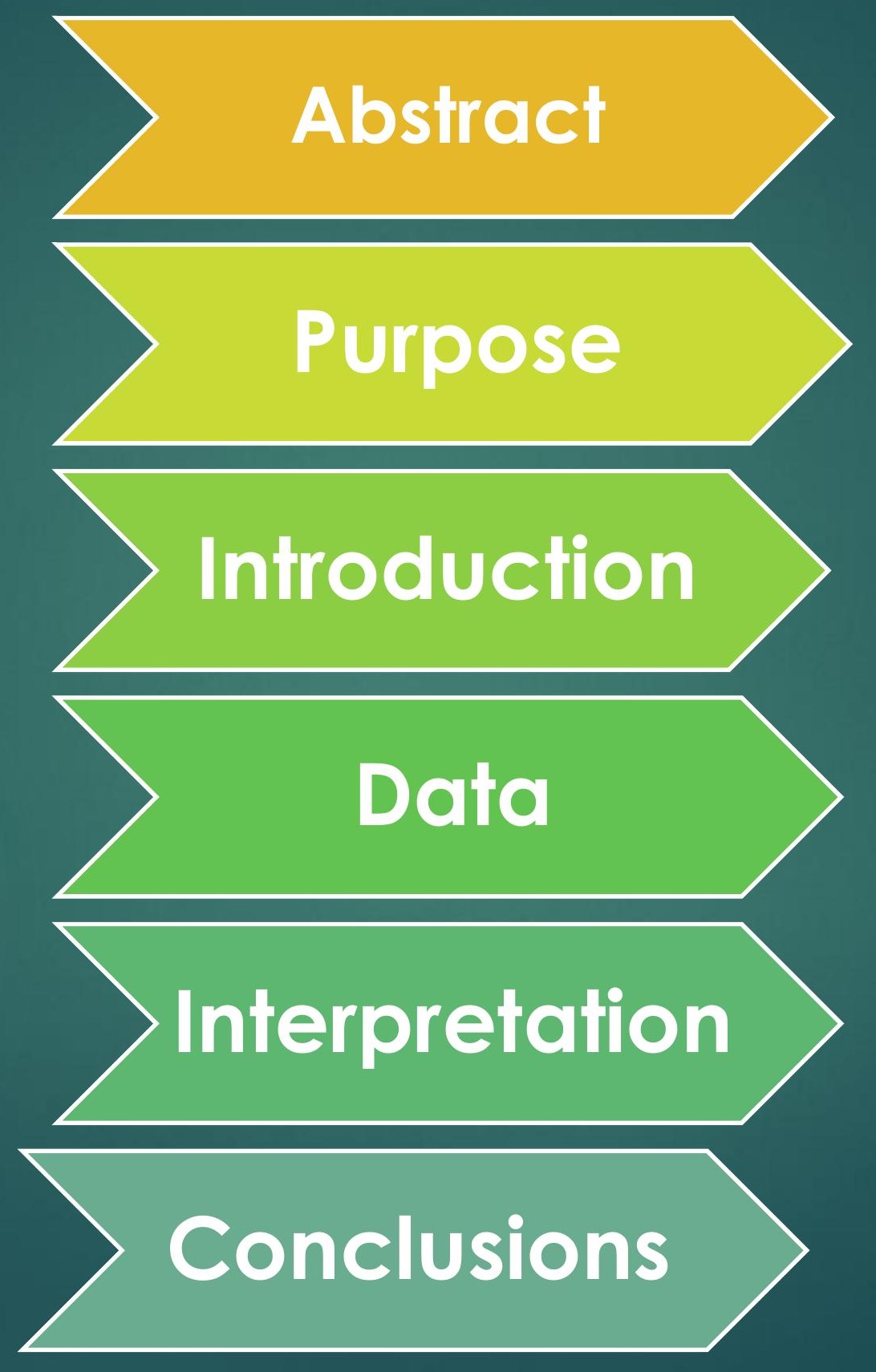

Tension or Balance: Each Section Vs Overall View

Department of Geosciences College of Arts and Sciences

\section{Abstract Due Before Research Completed}

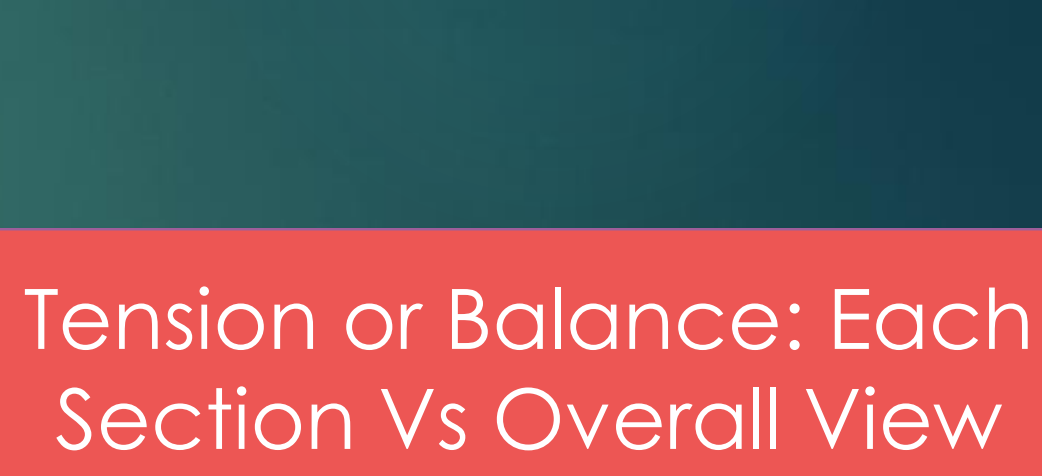




\section{Scientific Method}

$\checkmark$ Details

$\checkmark$ Provided Sections

- Explanation

Guidance

$\checkmark$ Discuss Each Week

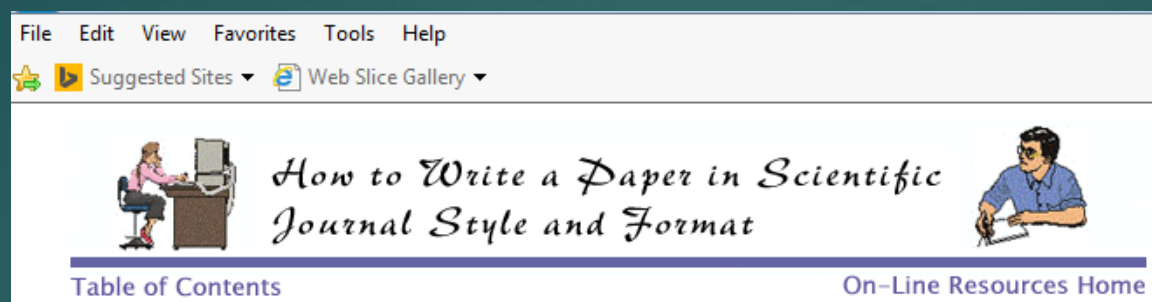

The Structure, Format, Content, and Style of a Journal-Style Scientific Paper

| Table of Contents $\mid$ FAQs $\mid$ PDF Version |

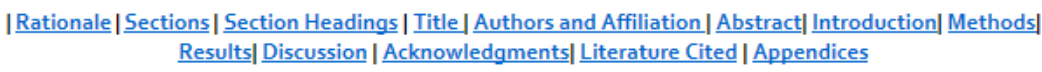

\section{Why a Scientific Format?}

The scientific format may seem confusing for the beginning science writer due to its rigid structure which is so different from writing in the humanities. One reason for using this format is that it is a means of efficiently communicating scientific findings to the broad community of scientists in a uniform manner. Another reason, perhaps more important than the first, is that this format allows the paper to be read at several different levels. For example, many people skim 1 intes to find out what infom and Abstracts. Those wanting to go deeper may look at the Tables and Figures in the Results, and so on. The take home point here is that the scientific format helps to insure that at whatever level a person reads your paper (beyond title skimming), they will likely get the key results and conclusions.

Top of page

The Sections of the Paper

Most journal-style scientific papers are subdivided into the following sections: Title, Authors and Affiliation, Abstract, Introduction, Methods, Results, Discussion, Acknowledgments, an website descikes the styte, content, and format associated with each section.
Department of Geosciences College of Arts and Sciences

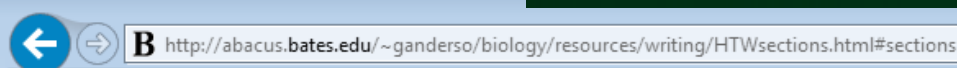
File Edit View Favorites Tools Help

绝

The Sections of the Paper

Most journal-style scientific papers are subdivided into the following sections: Title, Authors and Affiliation, Abstract, Introduction, Methods, Results, Discussion, Acknowledgments, and Literature Cited, which parallel the experimental process. This is the system we will use. This website describes the style, content, and format associated with each section.

The sections appear in a journal style paper in the following prescribed order:

\begin{tabular}{||c||c||}
\hline \multicolumn{1}{|c|}{ Experimental process } & Section of Paper \\
\hline \hline What did I do in a nutshell? & Abstract \\
\hline \hline What is the problem? & Introduction \\
\hline \hline How did I solve the problem? & Materials and Methods \\
\hline \hline What did I find out? & Results \\
\hline \hline What does it mean? & Discussion \\
\hline \hline Who helped me out? & Acknowledgments (optional) \\
\hline \hline Whose work did I refer to? & Literature Cited \\
\hline \hline Extra Information & Appendices (optional) \\
\hline
\end{tabular}

Section Headings:

Main Section Headings: Each main section of the paper begins with a heading which should be capitalized, centered at the beginning of the section, and double spaced from the lines above and below. Do not underline the section heading OR put a colon at the end.

Example of a main section heading:

INTRODUCTION

Subheadings: When your paper reports on more than one experiment, use subheadings to help organize the presentation. Subheadings should be capitalized (first letter in each word), 


\section{Weekly Deadlines}
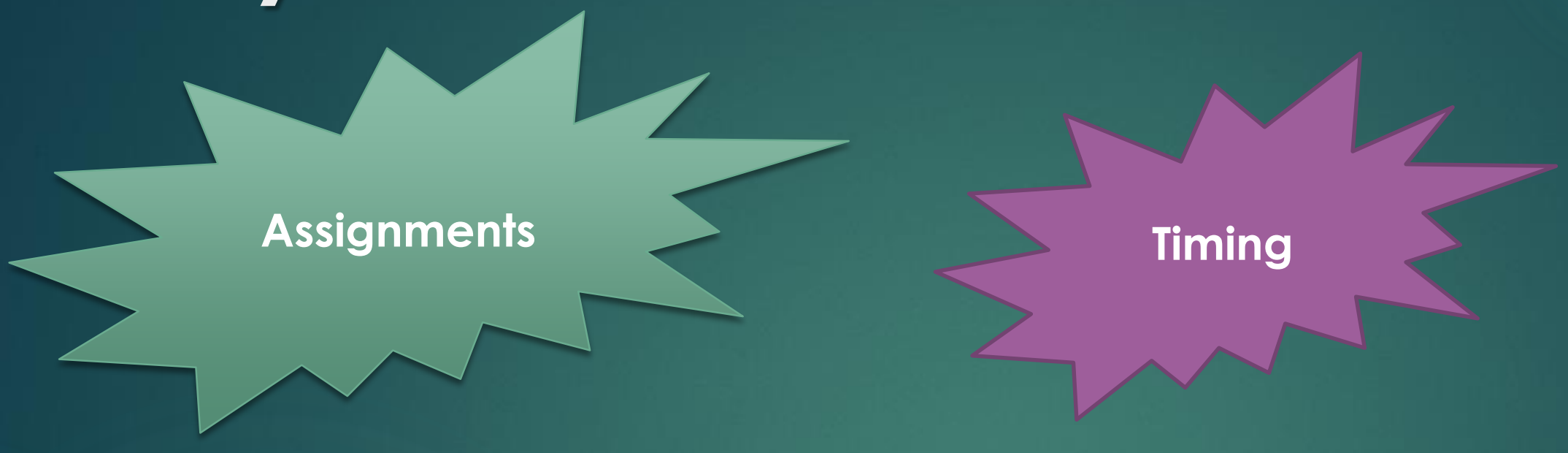

Department of Geosciences College of Arts and Sciences

\begin{tabular}{|c|c|c|c|c|c|c|}
\hline $\begin{array}{l}\text { Topic } \\
\text { Agreement } \\
1 / 24 / 17\end{array}$ & $\begin{array}{c}\text { Abstract to } \\
\text { Wayne } \\
1 / 31 / 17\end{array}$ & $\begin{array}{c}\text { Abstract } \\
\text { Submitted } \\
2 / 7 / 17\end{array}$ & 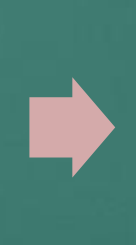 & $\begin{array}{l}\text { Class } \\
\text { Progress } \\
\text { Updates }\end{array}$ & $\begin{array}{c}\text { Poster to } \\
\text { Wayne } \\
3 / 21 / 17\end{array}$ & $\begin{array}{c}\text { Poster } \\
\text { Displayed } \\
3 / 29 / 17\end{array}$ \\
\hline
\end{tabular}

\section{$60 \%$ of Class Grade}

\section{$410 \%$ of Grode}

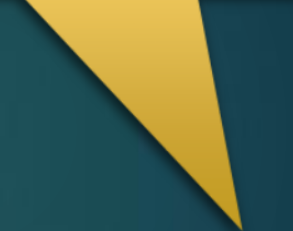




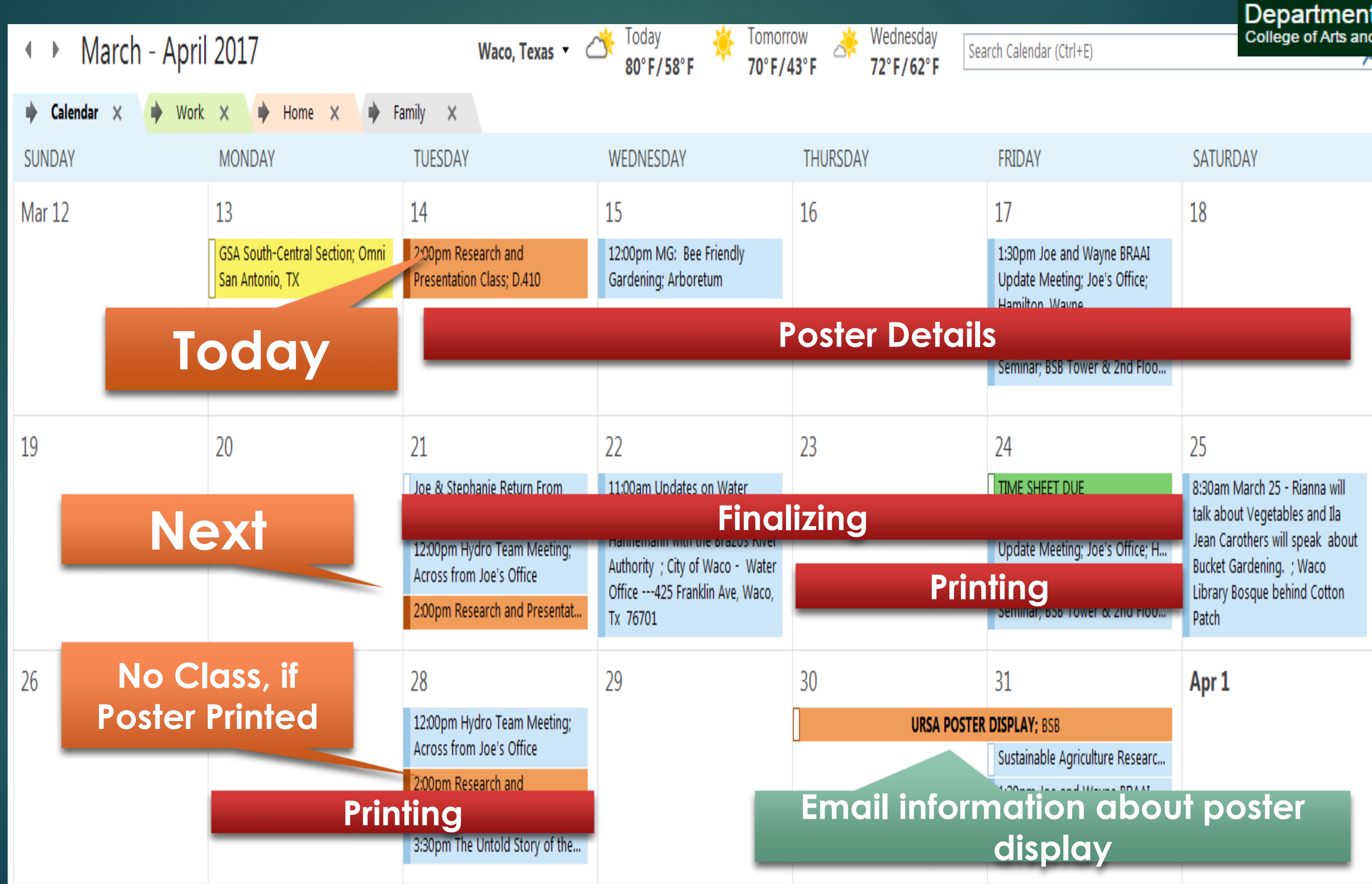




\section{Presentations}

Dach Student To Present

> Small Class Size: About Ten

- Peer to Peer Improvement

- Like the Work Place

- Students Added Things I Missed

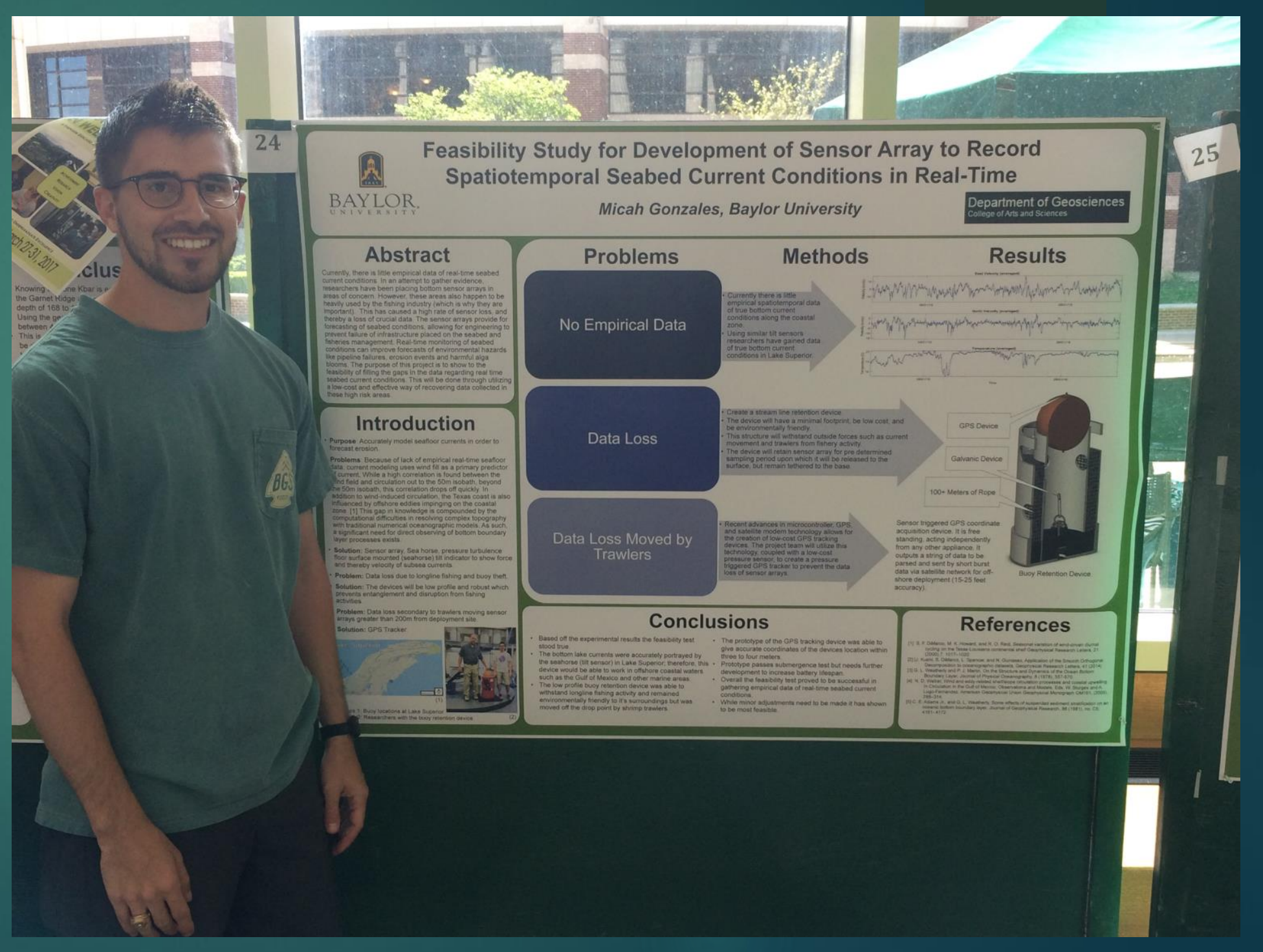




\section{Diversity of Topics}
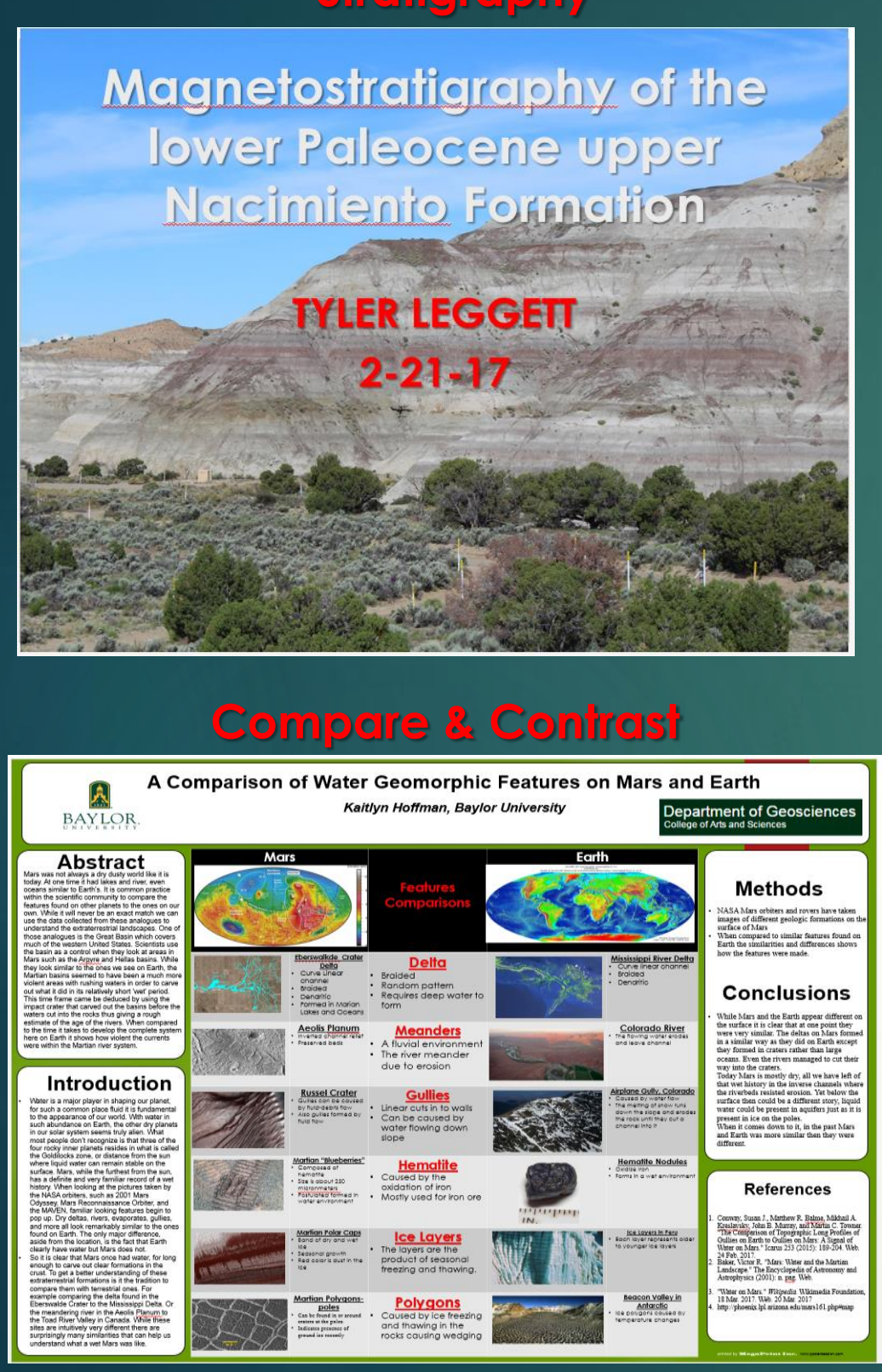
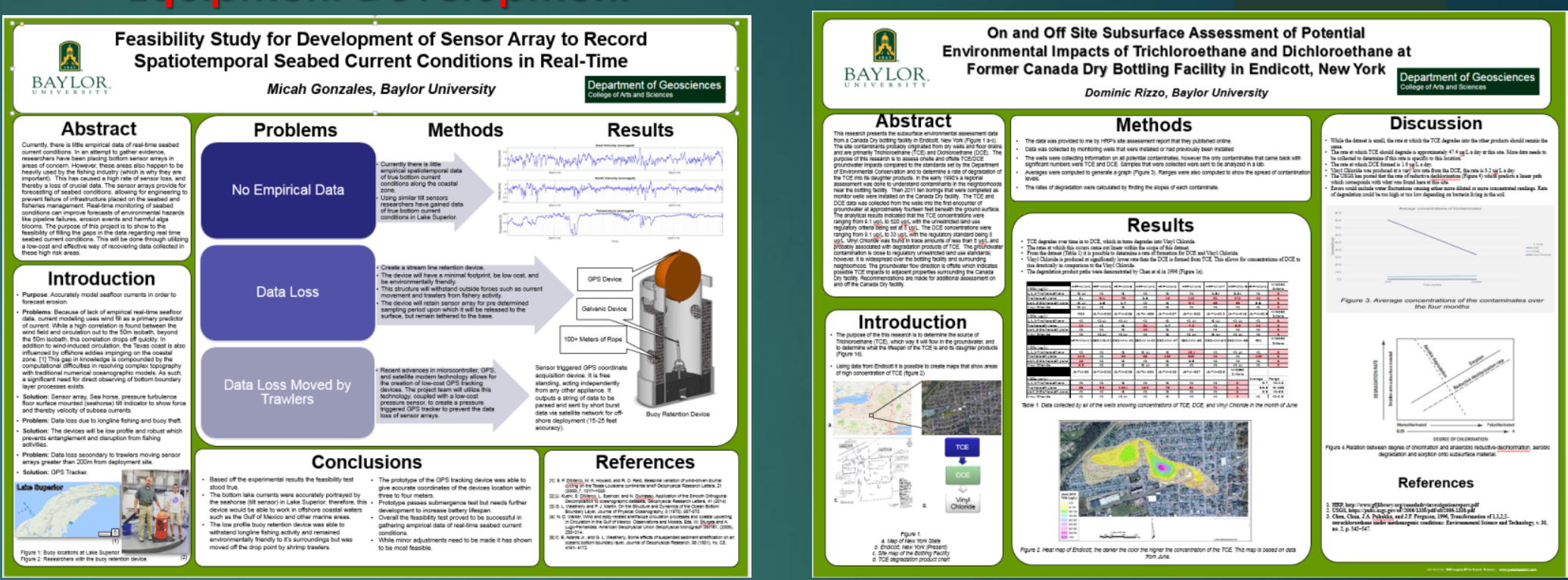

$$
\text { Igneous Petrology }
$$
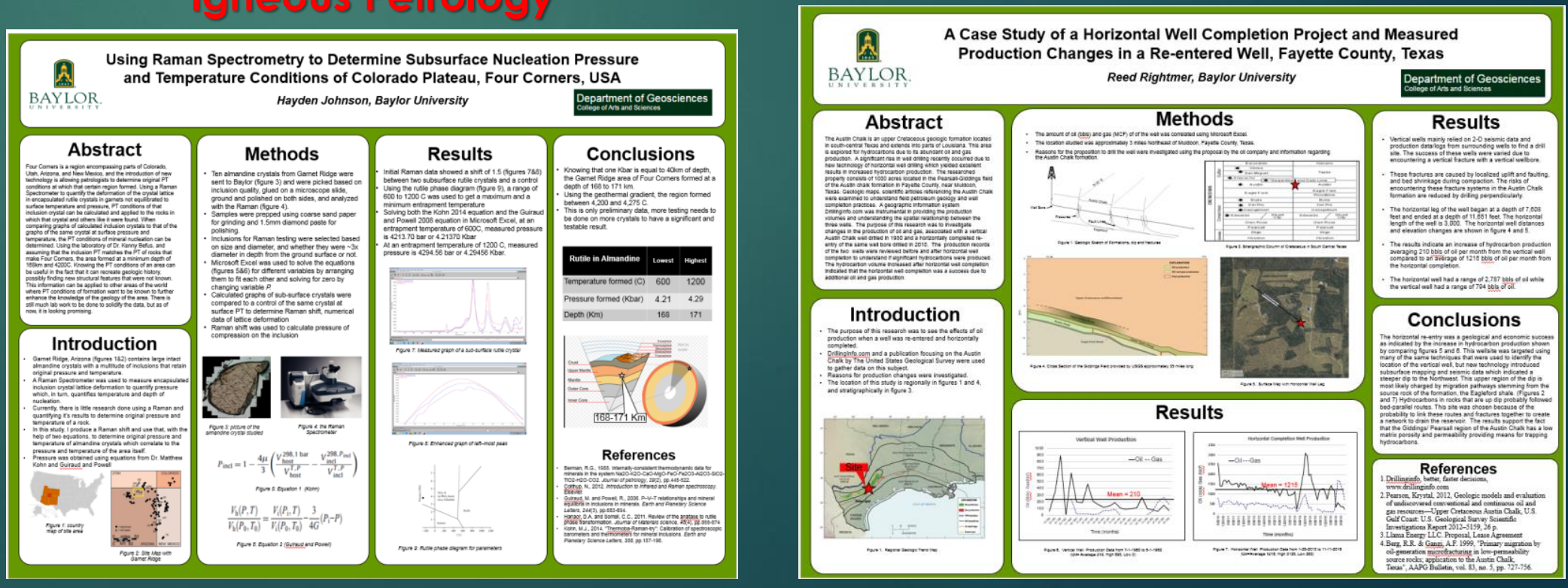


\section{Portfolio}

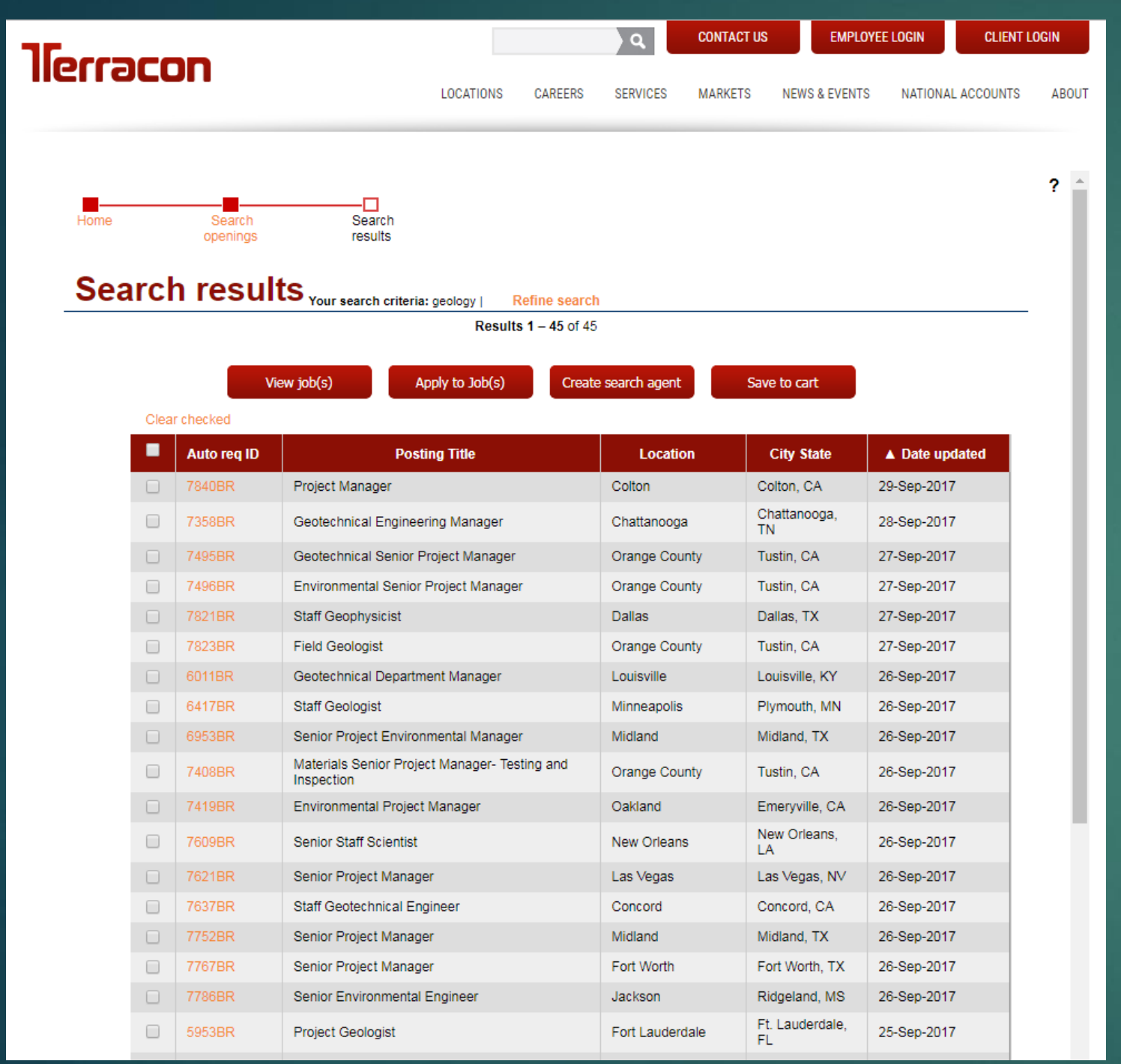

Internships \& Careers

Department of Geosciences College of Arts and Sciences

MENU $\equiv$

UNDERGRADUATE ADMISSIONS

\#WFU21 Apply

Visit - Financial Aid

Our Philosophy

Academics

Campus Life

\section{ADMISSIONS}

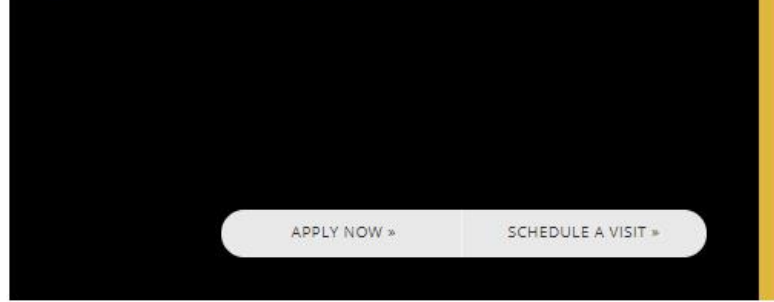

TURN WHO

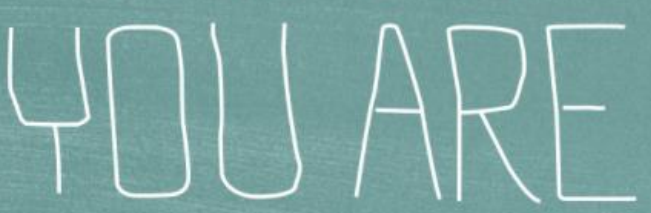

INTO WHAT

YOULL BE

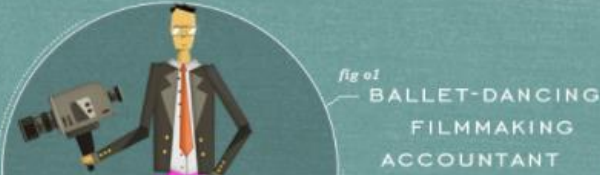

We're different. Like everyone.

More than beautiful brick buildings, technology or national rankings, people make Wake Forest the place it is. People who love challenge as much as they love learning, and the pportunity to engage all of who they are in search of what ey were meant to become. Please make yourself at home.

OUR PHILOSOPHY

EDUCATING THE WHOLE PERSON

Graduate School 


\section{Improvements}

\section{Writing}

Department of Geosciences College of Arts and Sciences

\section{Teacher's Input}

Stages 
- Most common problem

$\checkmark$ Not telling a story

- Clear and Logical

$\checkmark$ Peer to Peer

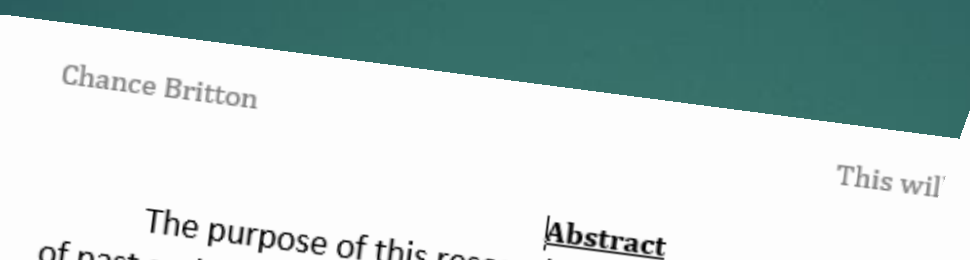

The purpose of this research is to act

alter (pollute) the land practices. There assess the surfact becoming a majo quality of clean pure are different fac

flows carry salts, polluting activity in mater. Growth of aquac

leachates such as nitrogents and pesticides. Tile drain. Irrigation return

dissolve the oxygen any to surface waters. The drainage rapidly carries

environmental assessm animals in the water These factors will poten*

and a tributary of Lessment will consist of three ne to survive. TI

issues, 3 water sample Tehuacana Creek.

streams on the samples will be taken from. To asc

taken to perfo property. These taken from eact

nitrate, the rorm test to measure the

TCEQ stand conductivity (salts present), $\mathrm{pH}$ balance

to see the nord maximums and minimum Dissolved,

may, or may nality or irregularity of ths of each on

be provided in the affecting the surface results, leac

standard min tables to show compariso water on the

an understandined parameters. Too add the water s

results of the water surface geology and the assessment

scientific standarder samples will be com soils present on

compared to state stane

Department of Geosciences

College of Arts and Sciences

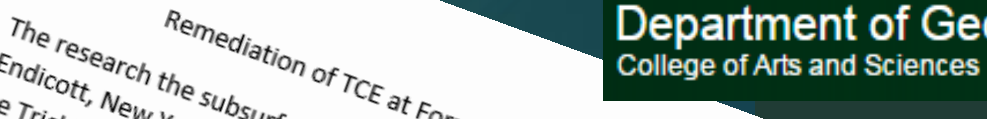

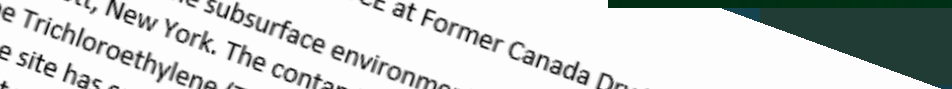

wever the rin to minated and Dichts at the assessment d ottling Facilit

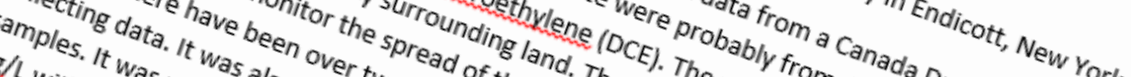

ug/ with the was reportedso colle twenty othe cont the data purpose dry wells o bottling

data in the sta teria bein that the ed by meas well drin ation. collecte of this reseand primg facility in

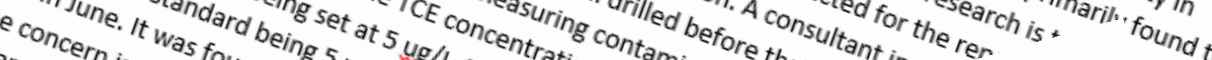

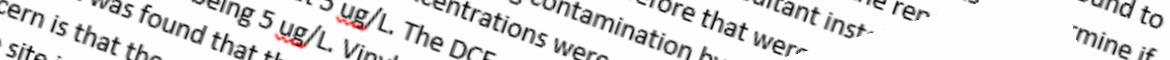

orting is transearea around contami Chloride concenterangi-

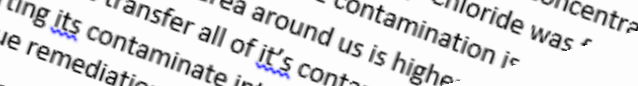

diation in ate ints cont is hish

six

to determine original PT conditions of four corners, USA

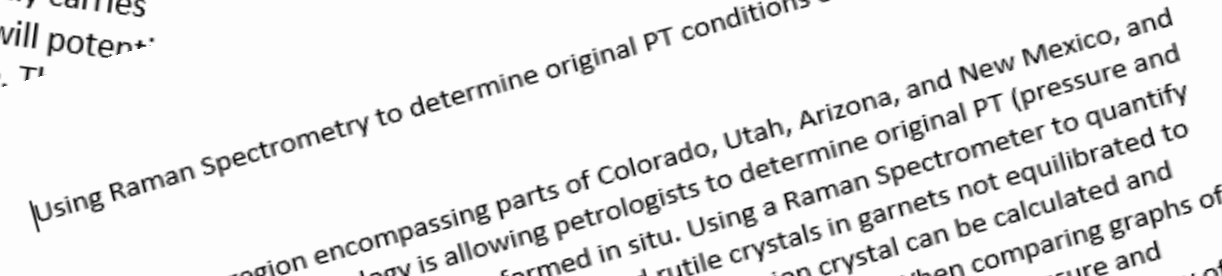
Corners is a region en nology is alls formed in ded rutile crysion crystal When compasure and of $D$.

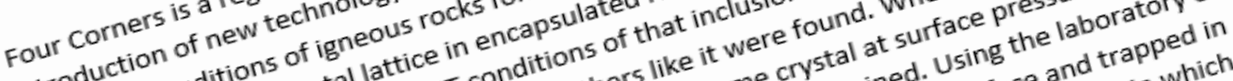
the introduce) conditions crystal lattice PT conditio others like same crystamined. S surface and rocks in which temperarmation of ure and press that crystal the graphs ation can be exposed at he PT of the formed at a depto to the def emperat $\mathrm{ks}$ in which to that of theral nucleasions, both ex matches egion was af the word has surface to the rocks crystals applied ed inclus PT condic tals with the PT of the four applied to o ther geolog calculat ture, the pret crystals suming hows that can be appes with othe tempera Befus, 10 gamere used. As nary data show ed here collaborates kenny Befsurface, wered, preliminadogy desc PT method the were $250 \mathrm{C}$. The the locations. $10 \mathrm{~km}$ and $250 \mathrm{cht}$. $10 \mathrm{~km}$ past histo ther regio assess pation to 0 


\section{Teacher's Input}

\section{$\checkmark$ Coaching but not doing}

$>$ Rewriting and Rewriting

> Organization

$\checkmark$ Logical
Wayne's comments, 1-31-16

Author: Kolton Sundquist

Post Title:

$$
\text { Abstract }
$$

Research in the geological aspects of land use planning is extremely important for the safest and most environmentally conscious development of the natural environment for use in urban building. The implication of safely using natural land for building purposes affects everyone that comes into contact with urban structures around the globe. The research being done involves a specific case study in Malibu, California, in which costal landslides led to the destruction of houses after the cliff side on which they were built had collapsed. In order to confront, contain, and eliminate the problem of losing urban structures due to landslides as a result of poor land use planning, the affected areas must be studied and the geological data collected must be used in the future land use of similar sites. The geological data collected from various sources will then be compiled and studied in order to determine the underlying geological constrains for the region. By studying the affected areas and using geological data collected a conclusion regarding the potential hazards and geological constraints of the area in question can be made. Proper land use planning and preventative measures can then be taken using the geological data compiled on the landslide sites found in Malibu. The resulting conclusions may also be applied to the improvement of land planning on sites with deferring geographical settings but similar geological make up as the case study site.

Did a very quick review...saw this link. Looks like there is enough information for your research topic. http://www.malibugeology.com/articles.html
Department of Geosciences College of Arts and Sciences
Q. Wayne Hami 1ton Add a title.

C. Wayne Hami Iton Could these geological inputs apply to more than buildings? For example citing dams, roads, tunnels? Primarily, buildings, but to roads and tunnels for example.

Q. Wayne Hami lton

I like the topic, suspect since it is California there are egulatory criteris for building on slopes. So possibly regulatory criteria for building on slopes.
regulatory input to your research topic. Also are there maps that would depict past landslides
and help with predicting future landslides. Maps and photos add a lot to your poster.

O. Wayne Hami lton Can you add any potential hazards here? Keep it brief, but list what you know now.

C. Wayne Hami 1ton

Like the "potential hazards" comment above, can rou tell me any of the "Beological constraints"? Suspect it would be soil or rock type, faults, fracture, groundwater depth...ect.

Q. Wayne Hami lton

Use "similar" instead of deferring. Furthermore I really like learnings being applying to other areas of poster/presentation/paper scope.

Wayne Hami lton 
Research Stages

혼

Beginning Excitement

$\frac{E}{0}$
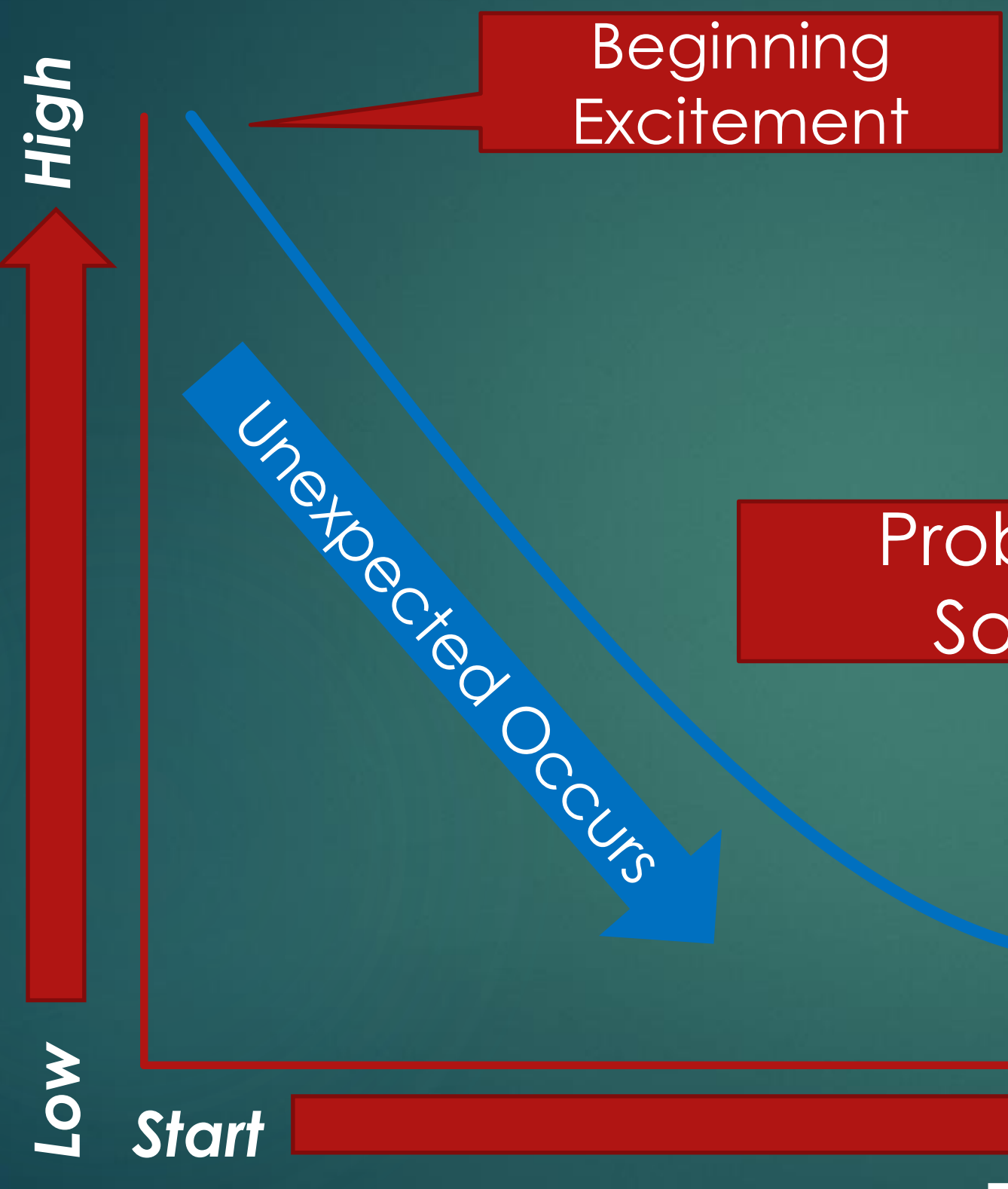

End
Department of Geosciences College of Arts and Sciences

Completed Elation

\section{Problems to} Solutions 


\section{Poster "Etiquette"}

$\checkmark$ Dialoe with

$>$ Visitors

$>$ Non-Geosciences

$\checkmark$ Faculty

$>$ Students

$\checkmark$ Judges

" at poster $\checkmark$ How to Keep motivated?

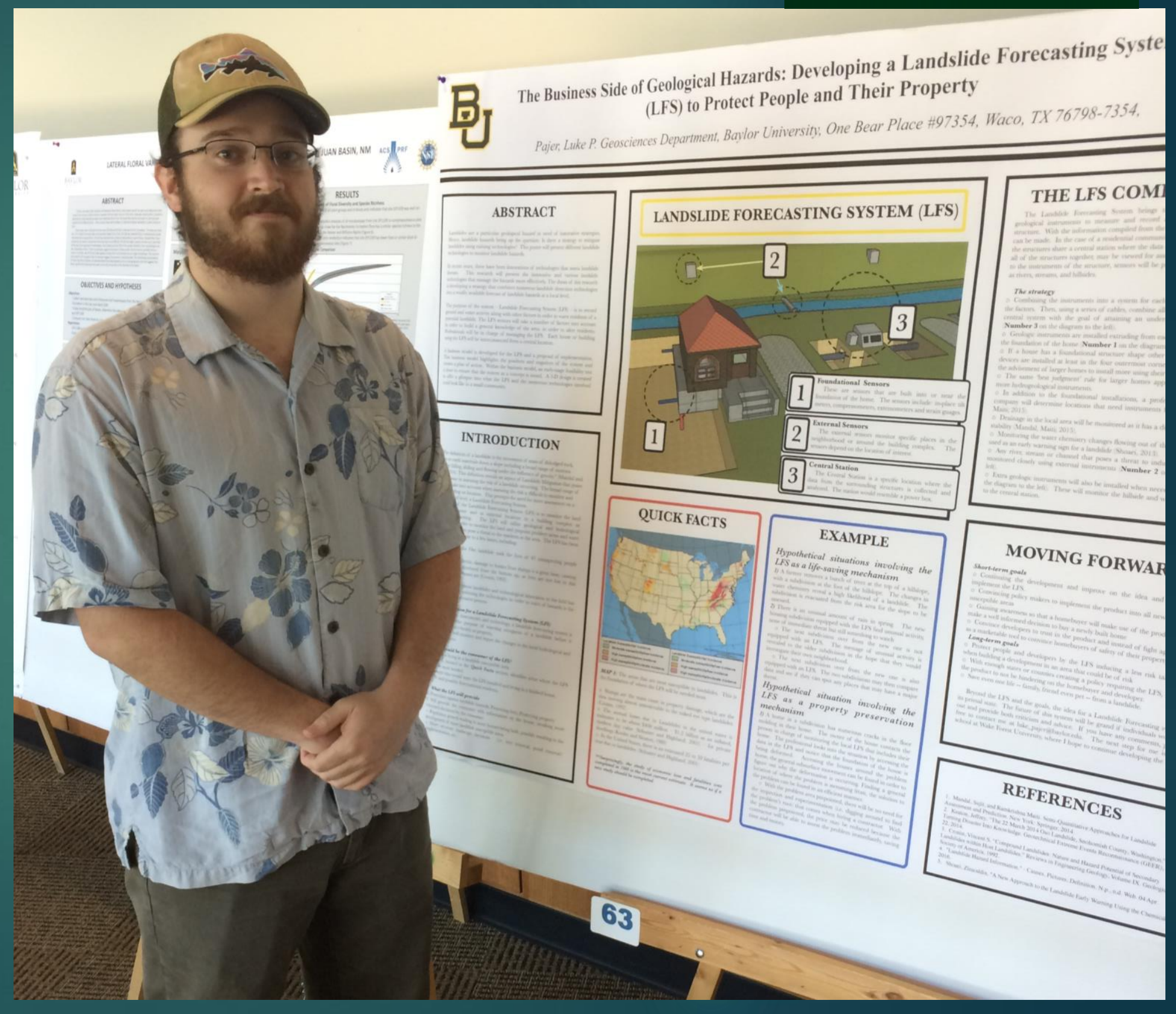




\section{Summary}

- Lessons Learning

> Student Motivation

> Teacher Leadership

$\checkmark$ Improvement Areas

$\checkmark$ Writing and Rewriting

$\checkmark$ Etiquette

$\checkmark$ Long Term Benefits

- Graduate School/Career

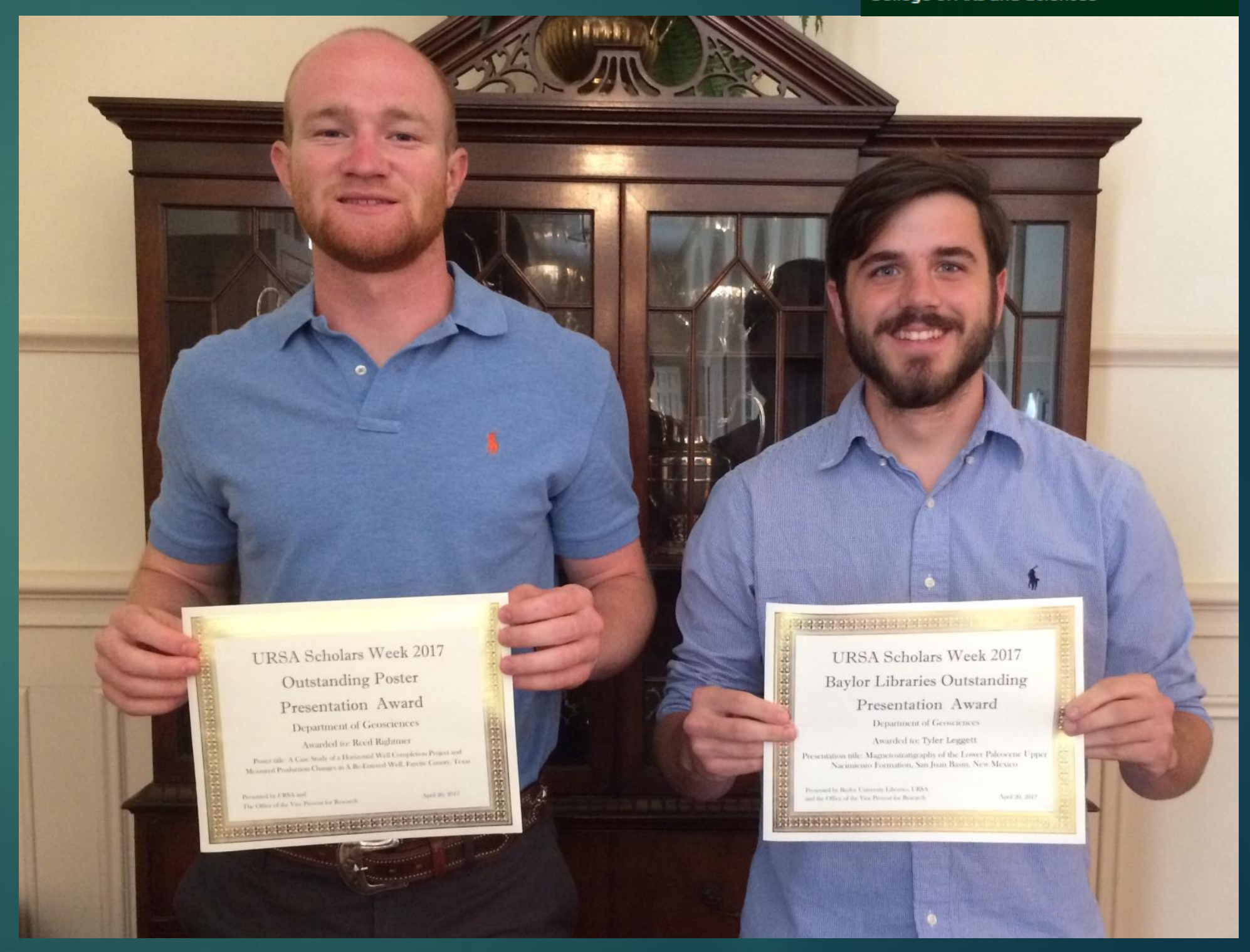


Poster: On the Cutting Edge: Fiffeen Years of Impacts on Geoscience Education

Monday, October 23, 4:30-6:30 p.s..

Booth 180

Postier 163-12

TEACHING A SUBSURFACE SIMULAJED SUBJECT OUTDOORS: HOW TO LEVERAGE JIME FOR FELD HYDROGEOLOGY 